\title{
THE PRAGMATIC ASPECTS OFHUMOR CREATION: A STUDY ON GRICE'S COOPERATIVE PRINCIPLES
}

\author{
Intan Pradita \\ Islamic University of Indonesia
}

\begin{abstract}
Humor is special tool of communication for its multifunction in any discourses. Its flexibility has been used by many people, of all social class, to deliver criticisms, tragedy of commons and happening issues in a funny way.This is because humor and culture are inseparable. Humor importance is undoubtedly effective to reveal the codes in cultures, politics, and education. The creation is interesting to discuss in this essay because it demands creativity, and its acceptance asks for high cognitive ability. However, a wrong perception of humor which is caused by different cultural background, and lackness of language competence is the core problem that may create missunderstanding. Through linguistics point of view, conversational principles constructed by Paul Grice is chosen as the approach of humor analysis.
\end{abstract}

Keywords: pragmatics, cooperative principles, flouted maxims

\section{INTRODUCTION: LANGUAGE AND HUMOR}

Human basic needs involve the primal necessity, which is to communicate one another. This is related to the paramount society demand, that everyone must be able to build a good communication. It is known that communication involves two participants; they are the speaker, and the hearer. The indicator of a good communication is both participants get the idea of the speaker intended to say. If both of them do not get the idea, then a poor communication happens (Hofmann, 1993: 5).

The same thing also happens to humor understanding. It requiresa hearer to have a higher capability of understanding situational context and background knowledge whichexists by observing the relation between the language use and situation of both participants.Having a good background knowledge can be achieved through havingboth good language proficiency and social issues 
understanding. Thus, it can be concluded that understanding humor requires the same things as daily conversation does. The difference is only in the final observable response, laugh.

\section{Humor}

Humor is closely related to human daily life as a form of style as well as a form of popular culture. Raskin (1985: 95) defines humor as the quality of action, speech, or writing which excites amusement: oddity, socularity, facetiousness, comicality, and fun. Humor also means the faculty of perceiving what is ludicious or amusing, or of expressing it in speech, writing, or other composition; jocose imagination or treatment of a subject. These characteristics of humor contribute to people's cognitive development and communication skills in the matter ofits functions.

Langan-Fox et al (2007: 218) explain that there are two functions of humor. The first is psychological function. Humor is a complex mental absurdity based on the interplay and multiple cognitive-affective processes. Therefore, understanding humor can improve people's cognitive-affective ability for having a good comprehension of language interplay. The second is communicative function. Humor is a form of social skill that leads to greater acceptance and influence in interpersonal relation. It provides flexibility in the communication of messages that might otherwise be rejected.

As a conclusion,people create humor through language interplay such as incongruity, amusement, absurdity, secularity and facetiousness. Humor creation affects both individual and social life of a person. Individually, since humor applies language interplay, it stimulates multiple cognitive-affective processes. Thus, it affects to the improvement of cognitive-affective ability of a person. Related to the social impact, since humor is a flexible medium of communication, it sends messages that might be rejected. Thus, humor is useful to share criticisms on certain social issues.

Additionally, Berger (1993: 49) constructs the morphology of humor. There are four terms underpinning humor, they are sarcasm, satire, slapstick, and stereotypes. In order to make it clearer, the researcher will explain them one by one. The first is sarcasm. It stems from the Greek sarkazein, "to fear the flesh, to bite". It involves the use of cutting, contemptuous, and 'biting' remarks. People deliver 
sarcasm often in a hostile manner. They use sarcasm as a stance, as an everyday manner of dealing with people.Sarcasm may generate some humor but it tends to be a costly kind of humor, unless the sarcasm is directed towards oneself and turned into a form of victim humor.

The second term that builds the morphology of humor is satire. Satire is one of the most important literally forms of humor and has been used by writers and engaged the attention of scholars and critics for thousands of years. Generally, it attacks the status quo and can be seen as a force for resistance, though this is not always the case. Some satirist attacks those who are critical of the status quo, but satire generally pokes fun at those in power. Satire is rather general technique of humor that makes use of many techniques discussed in this glossary: ridicule, exaggeration, insult, (invidious) comparison, and so on. Satirist attack specific individuals, institutions, or happenings.

The third is slapstick, is a physical humor that often involving degradation by action. The throwing of a pie in the face of a person is an externalized, objectified form of an insult. Slapstick involves all kinds of physical actions that amuse people such as slipping on bananas, sliding around on greasy floors, getting pies in the face, being hit with mops. Slapstick feeds on an inner sense of egalitarianism that people have a feeling that all claims to superiority are invalid. Slapstick is a kind of "democratic" degradation that is tied to a sense we have that everybody are all humans and the similarities between people are more important than the artificial differences created by social institutions.

The last term that constructs the morphology of humor is stereotype. Jokes involving stereotypes can be described as generalized insults attacks on races, religious, ethnic groups, etc. However, there is more to the humor of stereotypes than that. Stereotypes are useful to writers and comedians because these are instant (pseudo) "explanations" of behavior that enable people to understand "motivation". Thus, Scots are stereotyped as cheap, Polish people are stereotyped as dumb, Jews as materialistic, English as snobs, and so on.

As a conclusion, analyzinghumor means considering not only incongruity, absurdity, sarcasm as noted in pragmatics, but also satire, stereotype and slapstick to generate the morphology of humor as noted in socio-cultural background. 


\section{Pragmatics}

The subject of pragmatics is popular in linguistics today since it is foundthat many linguistic researches use pragmatics as the approach. However, years ago, pragmatics tends to be treated as a theory that is used to analyze the recalcitrant data that could be conveniently stuffed and could be forgotten. Recently, many linguists and philosophers argue, so does Leech (1983: 1) that people cannot really understand the nature of language itself unless they understand pragmatics: how language is used in communication.

According to Yule (1998: 3), pragmatics is concerned with the study of meaning as communicated by a speaker (or writer) and interpreted by a listener (or reader). It has no more to do with the analysis of what people mean by their utterances than what the words or phrases in those utterances might mean themselves. Pragmatics is the study of speaker's meaning. Related to humor understanding, Hofmann (1993: 273) explains that whenever language is used, there is a speaker and his intent. This ultimate intent is hidden behind the literal meaning of what is said. Gaps between the literal meaning of a sentence and what it is used to convey is studied under the broad name of pragmatics. In non-literal uses of sentences, the idea conveyed is not the same as the meanings of the words. For examples exaggeration, metaphor, sarcasm, and irony. These non-literal sorts of sentences are constructed in Cooperative Principle.

Leech (1983: 5) tries to distinguish the 'language' (langue) and 'language use' (parole) that has centered on a boundary dispute between semantics and pragmatics. Both fields are concerned with meaning, but the difference between them can be traced to two different uses of the verb to mean:

\section{[1] What does X mean? [2] What did you mean by X?}

Semantics traditionally deals with the meaning as a dyadic relation as in [I], while pragmatics deals with meaning as a triadic relation, as in [2]. Thus, meaning in pragmatics is defined relative to a speaker or user of the language, whereas meaning in semantics is defined purely as a property of expressions in a given language, in abstraction form particular situations, speakers, or hearers.

In the end, it is known that pragmatics deals with speaker's meaning, how language used in communication and the impression of specific utterance, which has no clear meaning. Therefore, pragmatics is useful to analyze the speakers intend to convey and the implication of their utterance. It observes the meaning of utterance by considering the relativity of a speaker or user of the language. 


\section{Pragmatic Aspects of Humor}

Wijana (1995: 8) explains that humor can be analyzed through linguistics; this is because humor involves incongruity and conflict. Aspects of incongruity and conflict are explained in linguistics through the norms of pragmatics both textual and interpersonal. Textually, the incongruity is done by violating cooperative principle, whereas the interpersonal incongruity is done by violating politeness principle.

Another researcher, Raskin (2008: 101) explains that humor creation is obtained through manipulating some rules of communication such as speech act, presupposition, precondition, and conversational implicature. He also said that both speaker and hearer should share the same knowledge or experience. They also should shareabout speech event. It is the awareness of members of a society concerning the significance of interaction between linguistic form and sequences of action in speech. Therefore, understanding humor requires the ability to interpret what the speaker's imply in his or her utterance. To evoke this ability, the hearer has to understand not only socio-cultural background but also the incongruity of the humorous utterance.

Related to humor creation and humor understanding, participants must have the ability to interpret what the speaker intend to convey. It includes the ability to infer the cooperation of both the speaker and the hearer, especially regarding share social and cultural knowledge, and the ability to find the sense of fun about what is explicitly stated. Pragmatics is the study of menaing that deals with this abilities. Thus, pragmatics is preferable to be the approach of humor understanding.

Additionally, Finch (2000: 168) explains that in order to retrieve an interpretation of utterances or the connections between utterances, the reader should infer something. The act of inference is a process that someone must go through to get from literal meaning of what is written to what the speaker intended to convey. The amount of inferring the meaning, thatspeakers expect listeners to undertake depends on the degree of shared knowledge between them.

\section{The Cooperative Principle}

The term implicature, suggested byGrice in Crystal (1997: 191) refers to what a speaker can imply, suggest, or mean differently from what the speaker 
literally says. Furthermore, conversational implicature refers to the implication, which can be deduced, from the form of utterance, based on certain cooperative principle that governs the efficiency and normal acceptability of a conversation. Thus, the notion of conversational implicature is derived from a general principle of conversation, which is known as Cooperative Principle (Brown and Yule 1983: $31)$.

The example of Grice's conversational implicature is the utterance; "have you got any cash on you?" where the speaker really wants the hearer to understand the meaning. The hearer then answers; "Can you lend me some money? I don't have much on me". In this case, the speaker implies a message that is not found in the plain sense of the sentence. Then, the hearer is able to infer this message in his utterance by appealing to the rule governing successful conversational interaction. Grice proposes that implicature as the hearer's utterance can be calculated from the speaker utterance by understanding three things; the usual linguistic meaning of what is said, the contextual information (shared or general knowledge), and the assumption that the speaker is obeying the cooperative principle.

Grice's cooperative principle assumes that people cooperate in the process of communication in order to reduce misunderstanding (Finch, 2000: 159). The principle states, "Make your contribution such is required, at the stage at which it occurs by the accepted purpose or direction of the talk exchange in which you are engaged". Additionally, Leech (1983: 82) explains that CooperativePrinciple enables one participant in a conversation to communicate on the assumption that the other participant is being cooperative. As a result, Cooperative Principle has the function of regulating what someone says so that it contributes to some assumed illocutionary or discourse goal(s).

According to Grice in Leech (1983: 7-8), there is a general assumption underpinning all utterance interpretation. This interpretation is guided by a CooperativePrinciple, in which a speaker and hearer are engaged in some shared goal. The elements of Cooperative Principles are:

(1) Maxim of quantitywhich requires to make your contribution as informative as is required (for the current proposes of the exchange).

(2) Maxim of qualityDo not make your contribution more informative than is required.Do not say what you believe to be false. Do not say that for which you lack adequate evidence. 
(3) Maxim of relationMake your contribution relevant

(4) Maxim of mannerBe perspicuous.Avoid obscurity of expression.Avoidambiguity.Be brief(avoid unnecessary prolixity).Be orderly

Defining maxim of quantity and maxim of quality, Leech (1983:84) proposes that maxim of quantity and quality can be considered together since they frequently work in competition with one another: the amount of information speakergives is limited by speaker's wish to avoid telling an untruth. A more detailed version of the same maxim formulated by O'Hair (1969: 45) in Leech (1983: 85)

"Unless there are outweighing good reasons to the contrary, one should not make a weaker statement rather than a stronger one if the audience is interested in the extra information that could be conveyed by the latter.'

Another form of maxim is maxim of relation that requires us to be relevant to what is said and to be relevant to the context. Conversational goals may include both social goals and personal goals (Leech, 1983: 94). For example, if there is a person asks, "Where's my box of chocolates?" the answer should be the description of a location where the box is placed, such as "It's in your room" or "It's in the table". However, there is another answer, "The children were in your room this morning". The one who answer in that way does not mean $\mathrm{s} /$ he is not cooperative, but there is an implication that is derived. She has explained the place of the box, which is in the room and brought by the children. Additionally, Black (2006: 24) explains that the maxim of manner is very much a matter of convention in such situations, but the maxims of quantity, quality, and relation are supposed to be observed by cooperative speakers

However, according to Thomas (1995) in Cutting (2002: 40), a speaker violates a maxim when he knows what the hearer will not know the truth. He also knows that the hearer will only understand the surface meaning of the words. They intentionally generate a misleading implicature.Maxim violation is unconsciously, quietly deceiving. The speaker deliberately supplies insufficient information, says something that is insincere, irrelevant or ambiguous, and the hearer wrongly assumes that they are cooperating. Therefore, even though the function of CooperativePrinciple is to govern the efficiency and normal acceptability of a conversation, the violation of those four maxims exists. 


\section{Flouted Maxims}

Black (2006:25) explains that the maxims are not always observed, and the failure to do so can take a number of forms.

a. Opting out.

Opting out means making clear that one is aware of the maxim, but isprevented for some reason from observing it. Politicians and reportersobserving an embargo on the publication of news are in this situation.

b. Violating maxims.

Violating maxims is often with the intention to mislead, this is often a quiet act, also known as lying.

c. Aclash between maxims

A clash arises when one cannot be fully co-operative. For instance, to fulfill one maxim (for example, of quantity) might require one to break another (of quality), in a situation where one is not certain of the accuracy of some information, and hence uncertain whether to say something which may be helpful, but where one's evidence is inadequate. One may therefore hedge one's contribution. The examples of a clash are clauses such as "I understand that" or "It seems to me."

d. Flouting

Flouting is the most interesting way of breaking a maxim. One makes clear to the hearer that one is aware of the co-operative principle and the maxims, so that the audience is led to consider why the principle or a maxim was broken. The assumption, in other words, is not that communication has broken down, but that the speaker has chosen an indirect way of achieving it.

As noted in Meaning in Interaction, (Thomas, 1995: 73) explains that there are two possibilities of conducting the maxims. The one is doing an observance of the maxim and the other is doing a non-observance of the maxim. The latter category was separated into five types; they are flouting, violating, infringing, opting out, and suspending maxims.Flouting is when the speaker blatantly fails to observe a maxim in which s/he has no intention of deceiving or misleading;

Violating happens when the speaker violates a maxim when he is liable to mislead the hearer to have such an implicature. The example is given in Cutting (2002: 40): 
Husband : How much did that new dress cost, darling?

Wife : Less than the last one

Infringing happens when there is neither an intention of generating an implicature nor an intention of deceiving the hearer due to imperfect linguistic performance such as a young child or foreign learner. Another form of nonobservance of a maxim is opting out. It is when the speaker opts out a maxim; s/he indicates unwillingness to cooperate in the way the maxim requires. In short, opting out is when the speaker appears uncooperative. The last non-observance of maxim is suspending a maxim. It is when there is no expectation on the part of any participants that the maxims will be fulfilled; hence, there is no implicature generated. Furthermore, it may also be cultural-specific to particular events.

Cuttting (2002: 37) defines flouting maxim as a condition when speakers appear not to follow the maxim but expect hearers to appreciate the meaning it implied. Just with an indirect speech act, the speaker implies a function different from the literal meaning of form; when flouting a maxim, the speaker assumes that the hearer knows their words should not be taken at face value and that they can infer the implicit meaning. There are four types of floutedmaxims, they are flouted quantity, flouted quality, flouted relation, flouted manner.

\section{Flouted Maxim of Quantity}

The speaker who flouts the maxim of quantity seems to give too little or too much information. The form of flouting is when the speaker breaks the rule which is giving information as required. One of the example is seen below.

A Well, how do Ilook?

B Your shoes are nice (laugh)

$\mathrm{B}$ does not say that the sweatshirt and jeans do not look nice, but he knows that A will understand that implication, because A asks about this whole appearance and only is told about part of it. This form of incomplete information may cause missuderstanding for the speaker. S/he asks for suggestions upon his/her look. Speaker B intentionally create a humorous expression by commenting the shoes only. In some cultures, this may cause anger. Fortunately, there is an additional expression in the brackets showing that speaker $\mathrm{B}$ is making fun of the shoes. 
Cook (1989: 31) explains another definition of flouted maxim of quantity. It happens when the speaker blatantly gives more or less information that the satiation requires. The purpose is to mark the use of figure of speech in one's utterance.

Another exampleto show the existence of flouting maxim of quantity is the dialogue as noted in Shakespeare's Hamlet, scene ii:

Polonius: What do yu read, my lord?

Hamlet: Words, words, words

Polonius: What is the matter, my lord?

Hamlet: Between who?

Polonius: I mean, the matter that you read, my lord?

Hamlet: Slanders, sir: for the satirical rogue says here that old men have grey beards, that their faces are wrinkled, their eyes purging thick amber and plum-tree gum, and that they have a plentiful lack of wit, together with most weak hams: all which, sir, though I most powerfully and potently believe, yet I hold it not honesty to have it thus set down; for yourself, sir, should grow old as I am, if like a crab you could go backward.

The conversation above clearly explains that Hamlet flout maxim of quantity in order to refuse to answer Plonius' question. As said previously, both participants in a conversation must be as informative as required, neither more nor less. Provided example shows that Hamlet does not perform both.

\section{Flouted Maxim of Quality}

Cook (1989: 31) defines flouted maxim of quality as a condition when the speaker says something untrue or lack of evidence. However, she does not try to deceive the hearer in any way, so the hearer was forced to look for another plausible interpretation. The purpose of flouting this maxim is to create prolixity, to be rude and blunt.

The definition is more developed by Cutting (2002: 37) who proposes that flouting quality can be done in several ways. First, they may quite simply say something that obviously does not represent what they think. For example: 
When Sir Maurice Bowra was Warden of WadhamCollege,Oxford, he was interviewing a young man for a place at the college. He eventually concluded that the young man would not do. Helpfully, however, he let him down gently by advising the young man, "I think you would be happier in a larger-or a smaller-college".

(Rees 1999:5)

When Sir Maurice says "I think you would be happier in a larger-or a smaller- college", which flouts the maxim if he knew that the student would understand what he was getting at, and hear the message behind his words.

Secondly, speakers may flout the maxim by exaggerating as in the hyperbole "I could eat a horse", or

"You know, I can crush rocks with my bare hands"

"It's raining cats and dogs"

"It took me years to find the perfect woman"

"Yes I'm starving too."

(Fussel and Kreuz, 1998: 96)

In which 'I'm starving' is a well-established exaggerating expression. No speaker would expect their hearer to say, "What, you could eat a whole horse?" or "I don't think you are dying of hunger -you don't even look thin.' Hearers would be expected to know that the speaker simply meant that they were very hungry. Hyperbole is often at the basis of humor as is depicted in the example below:

Remember that as a teenager you are at the last stage in your life when you will be happy to hear that the phone is for you.

(Leobowitz, 1985:368)

It is an exaggeration to say that adults are never happy to hear that the phone is for them, even though this may often be the case. Anybody reading this humorous line would know not to take it at its face value. Hyperbole as is defined by Murfin and Ray (2003:205) is a figure of speech that uses deliberate exaggeration to achieve an effect, whether serious, comic, or ironic. Some critics refer to hyperbole as overstatement.

Similarly, a speaker can flout the maxim of quality by using a metaphor, as in 'My house is a refrigerator in January' or 'It's only cost me a 
nickel'. Here again, hearers would understand that the house was very cold indeed, and the other person is trying to reduce other people's enjoyment. It is similar with interpreting the meaning behind the words, such as"Religion...is the opium of the people". Conventional euphemism can be put into this category too. When people say "I'm going to wash my hands" meaning "I'm going to urinate", and when they say "She's got a bun in the oven" meaning "I'm going to urinate". The implied sense of the words is so well established that the expressions can only mean one thing. Murfin and Ray (2003: 260) define metaphor as a figure of speech that associates two distinct things; the representation of one thing by another. For instance, in the sentence "That child is a mouse" meaning the image of a mouse is being used to represent the child, perhaps to emphasize his or her timidity.

The other two main ways of flouting the maxim of quality are irony and banter, and they form a pair. As Leech (1983: 144) says, that irony is an apparently friendly way of being offensive (mock-politeness), the type of verbal behavior known as "banter" is an offensive way of being friendly (mock-impoliteness). Thus, in the case of irony, the speaker expresses a positive sentiment and implies a negative one. If a student comes down to breakfast one morning and says "If only you knew how much I love being woken up at 4 am by a fire alarm", she is being ironic and expecting her friends to know that she means the opposite. Sarcasm is a form of irony that is not so friendly; in fact, it is usually intended to hurt, as in "This is a lovely undercooked egg you've given me here, as usual. Yum!" or "Why don't you leave all your dirty clothes on the longue floor, love, and then you only need wash them when someone breaks a leg trying to get to the sofa?"

Murfin and Ray (2003: 220) define irony as a contradiction or incongruity between appearance or expectation and reality. This disparity may be manifested in a variety of ways. A discrepancy may exist between what someone says and what he or she actually means, between what someone expects to happen and what really does happen, or between what appears to be true and what actually is true. Murfin and Ray also clarifies that there are several types of irony exist, all of which may be classified under one of three broad headings: verbal irony, situational irony, and structural irony. Verbal irony, also called rhetorical irony, is the most common kind of irony.

Verbal irony is characterized by a discrepancy between what a speakers or writer say and what he or she believes to be true. More specifically, 
a speaker or writer using verbal irony will say the opposite of what he or she actually means. Situational irony, also called irony of situation, derives primarily from events or situations themselves, as opposed to statements made by any individual, whether or not that individual understands the situation as ironic. It typically involves a discrepancy between expectation and reality.

The researcher in Murfinand Ray (2003: 425) also derive the description of sarcasm. They explain that sarcasm is intentional derision, generally directed at another person and intended to hurt. These five ways of creating flouting quality, untruth statement, hyperbole, metaphor, irony, and sarcasm can be used to analyze humor utterances because all of them involve the incongruity and the disparity as humor manifestations and the derision as one of American humor characteristics.

\section{Flouted Maxim of Relation}

If speakers flout the maxim of relation, they expect that the hearers will be able to imagine what the utterance did not say, and make the connection between their utterance and the preceding one(s). Thus, in
A :So what do you think of Mark?
B :Hisflatmate's a wonderful cook.

B does not say that she was not very impressed with Mark, but by not mentioning him in the reply and apparently saying something irrelevant, she implies it. Similarly, in the next, Noel Coward is said to have had this exchange, after his play Sirocco (1927) was booed:

Heckler :We expected a better play

Coward :I expected better manners.

(Sherrin 1995:29)

Grice thought that flouting the maxim of relation was possible, but many people have disagreed because whetherpeople observe or flout maxims, the utterances will always be taken as relevant to the preceding co-text.

\section{Flouted Maxim of Manner}

Cutting (2002: 39) explains that those who flout the maxim of manner, appearing to be obscure, are often trying to exclude a third party. Another 
definition of flouting manner is when the speaker says something extremely long-winded and convoluted and it is obviously no accident nor through any inabilities to speak clearly. The main purpose of flouting this maxim is to establish solidarity or humor. (Cook, 1989: 31).

The example of flouting manner asnoted in Cutting (2002: 39), the conversation between husband and wife:

A Where are you off to?

$B$ I was thinking of going out to get some of that funny white stuff for somebody

A OK, but don't be long-dinner's nearly ready

B speaks in an ambiguous way to avoid saying 'ice cream' and 'Michele' in order to make his daughter does not know because the ice cream is intended to be a surprise for Michele.

Another example showing flouted maxim of manner is one of the dialogues of Spongebob Squarepants Krabby Kronicles episode,

A: "And why do you put the hat to me Mr. Krab?"

B: “...From now on you'll be twice as busy, and I expect you to wear 2 hats 'cause along with your usually fry cooking suites, you're my new lead reporter for the new KrabbyKronicles!'”

These flouting maxims can be used to analyze humor because of the involvement of humor manifestation such as incongruity and absurdity. Further, flouting maxim requires both the speaker and the hearer to be able to interpret the meaning implied by each utterance.

\section{CONCLUSIONS}

Humor is a part of language habit that performs incongruity. Humor creation involves not only linguistic aspect, but also cultural aspect. The analysis shows that:

1. Cooperative principles are the elements of pragmatics that contribute to the conversational analysis.

2. Flouting maxims of cooperative principles are one of pragmatic phenomena that are able to be employed in humor creation linguistically. 
3. The use of figurative languages, ambiguity, irrelevant expressions, and too shot/long information are the method to create incongruity as the basis of humor creation.

\section{REFERENCES}

Berger, A.A. 1998. An Anatomy of HumorNew Jersey: Transaction Publishers.

Black, E. 2006. Pragmatics and Stylistics.Edinburg: Edinburg University Press Ltd.

Brown, G. \&G.Yule. 1983. Discourse Analysis. Cambridge: Cambridge University Press.

Cook,G. 1989. Discourse. Oxford: Oxford University Press.

Cutting, J. 2002.Pragmatics and Discourse, A Resource Book for Students. London and New York: Routledge.

Hoffman,Th.R. 1993. Realms of Meanings: An Intriduction to Semantcs. England: Longman Group UK Ltd.

Langan-Fox,J.et.al. 2007. Research Companion to the Dysfunctional Workplace: Management Challenges and Symptoms. Chelternham: Edward Elgar Publishers.

Leech, G. 1983. Fusions: A Sense of Place. USA: Center for Book Arts.

Raskin,V. 1985. Semantic Mechanism of Humor.Dodrecht Holland: D. Reidel Publishing Company 